\title{
SUSTAINABLE SYNTHESIS AND OPTIMIZATION OF ENGINEERING SYSTEMS
}

\author{
MILOŠ BOGATAJ ${ }^{1}$, LIDIJA ČUČEK ${ }^{1}$, TOMAŽ ŽULA², \\ STOJAN KRAVANJA ${ }^{2} \&$ ZDRAVKO KRAVANJA ${ }^{1}$ \\ ${ }^{1}$ Faculty of Chemistry and Chemical Engineering, University of Maribor, Slovenia \\ ${ }^{2}$ Faculty of Civil Engineering, Transportation Engineering and Architecture, University of Maribor, Slovenia
}

\begin{abstract}
The solutions to engineering systems should not only be feasible but should also be beneficial to all the pillars of sustainable development (economic, environmental and social) to the greatest possible extent. However, due to the inherent trade-offs among the three components of sustainable development, identifying such solutions is not a straightforward task. In this manuscript, we present a simultaneous approach for sustainable synthesis and optimization of engineering systems based on a mixed-integer (non)linear programming MI(N)LP. The approach aims at providing sustainable solutions and an insight into the trade-offs among the economic, environmental and social component of sustainable development. Maximization of a sustainability profit, which is a composite criterion comprised of economic, eco- and social profits, is applied in order to obtain the optimal sustainable solutions. The solutions are compared to those obtained by maximizing either pure economic profit or minimizing Green House Gas emissions. The approach is tested on two case studies and the results are compared. The first example is a simple example from the field of civil engineering. The example presents the synthesis/optimization of a 5.5 meters long cantilever beams. The second example represents supply chain synthesis/optimisation of a biogas production plant in Slovenia. The results for the first case study indicate that $23 \%$ increase in sustainability profit causes slight decrease in economic profit (6\%). On the other hand, the results for the second case study indicate that a slight increase in sustainability profit $(6 \%)$ causes a $27 \%$ decrease in economic profit. Nevertheless, the solutions obtained by maximizing the sustainability profit remain economically viable due to its composite nature that properly captures and reflects the trade-offs.
\end{abstract}

Keywords: engineering systems, optimization, synthesis, mixed-integer programming, cantilever structure, supply chain, sustainability, sustainability profit.

\section{INTRODUCTION}

Various optimization techniques have become recognized as key enabling tools for decision making in practically all fields of engineering. Many engineering problems require solutions that are not only feasible but also optimal with respect to a given objective or a set of objectives. These are commonly defined in terms of economic parameters, such as capital/operating costs, profit, return on investment, etc. However, the paradigm shift towards sustainable development and circular economy has revealed that what can be considered as an optimal design under purely economic objectives might not be optimal in terms of sustainability or circularity. For this reason, it is important that the optimization approaches encompass a suitable metric that properly reflects the economic, societal and environmental aspect. Several sustainability metrics can be incorporated into optimization problems, such as different footprints (e.g. carbon footprint), indicators (e.g. sustainable environmental performance indicator), indexes (e.g. sustainable process index), eco-profit [1], sustainability profit [2], and last but not least sustainability net present value [3].

In this manuscript, we focus on comparison among the solutions obtained by maximizing pure economic profit, minimizing greenhouse gas emissions, and maximizing the sustainability profit. The latter is a composite criterion comprised of economic, eco- and social profits. The definition of economic profit is well known. On the other hand, the eco- 
profit is defined as an analogy to the economic profit and is expressed in monetary units. It represents a difference between the environment unburdening (eco-benefit) and environment burdening (eco-cost). They are both based on eco-cost coefficients [4], monetary LCA measures representing marginal investment to be spend in order to prevent environmental burdens [5]. The eco-benefit mostly relates to the substitution of resources, technologies, product etc. harmful to the environment with environmentally more benign ones. Social profit is defined by aspects that fall on enterprise's shoulders for improving social status of employees and the local community.

The reminder of the manuscript is structured as follows. In Section 2, approach for simultaneous synthesis and optimization of engineering problems that contain discrete and continuous decisions is presented. In Section 3, two case studies (synthesis/optimization of cantilever beam and biogas supply chain) are described and the results obtained are compared under different objective functions. Finally, concluding remarks are provided in Section 4.

\section{MATHEMATICAL MODELING}

Most structural optimization strategies for synthesis and optimization of engineering problems start by postulating a superstructure. A superstructure is an abstract, often graphical, representation of possible structural alternatives that might be considered in the final design. These alternatives (i.e. discrete decisions) might represent different materials, different production technologies, different production locations etc. Such a representation is intuitive and facilitates translation of the discrete decisions into mathematical language.

In addition to discrete decisions, engineering problems contain continuous decisions. These arise in the mathematical description of individual engineering system. A system is often described by a set of linear and/or nonlinear constraints that assure the feasibility of the design. These constraints contain continuous decisions such as dimensions, weight, forces, temperature, pressure, etc. It has been shown that better designs could be obtained when both the discrete and continuous decisions are considered simultaneously. This could be achieved by formulating and solving a mixed-integer nonlinear optimization problem (MINLP), which encapsulates features of combinatorial and continuous nonlinear optimization simultaneously. In its most general form it can be represented as:

$$
\begin{aligned}
& \min _{x, y}=f(x, y) \\
& \text { s.t. } \\
& \mathrm{g}(x, y) \leq 0 \\
& x \in R^{n} \\
& y \in\{0,1\},
\end{aligned}
$$

where $f(x, y)$ is the objective function, $g(x, y)$ are the constraints, $x$ are the continuous variables and $y$ are discrete $(0,1)$ variables. In MINLP, at least one of the constraints or the objective function is nonlinear. These problems are hard to solve since they combine the combinatorial nature of mixed-integer programming and inherent difficulty of nonlinear programs (e.g. non-convexities) [6]. On the other hand, if all the constraints and the objective function in MINLP are linear, the problem reduces to a mixed-integer linear problem (MILP).

The objective functions considered in this work are economic profit (eqn (1)), $\mathrm{CO}_{2}$ emissions (eqn (2)) and sustainability profit (eqn (3)) and can be written in generalized form as:

$$
\min P_{\mathrm{E}}=(1-t)(R-E),
$$


where $P_{\mathrm{E}}$ is economic profit, $t$ tax rate, $R$ revenue, and $E$ expenses

$$
\min m_{\mathrm{GHG}}=\sum_{i} m_{\mathrm{Ui}} f_{\mathrm{CFEF} i} \text {. }
$$

In eqn (2), $m_{\mathrm{GHG}}$ represents greenhouse gas emissions in $\mathrm{CO}_{2}$ equivalent, $m_{\mathrm{U}}$ is unit mass, and $f_{\text {CFEF }}$ is carbon footprint emission factor

$$
P_{\mathrm{SUS}}=P_{\mathrm{E}}+P_{\mathrm{ECO}}+P_{\mathrm{SOC}} .
$$

The sustainability profit ( $\left.P_{\text {SUS }}\right)$ in eqn (3) is defined as a sum of economic profit, ecoprofit $\left(P_{\mathrm{ECO}}\right)$ and social profit $\left(P_{\mathrm{SOC}}\right)$.

\section{CASE STUDIES}

The two case studies presented in this section reflect two different views on optimization of a given product. The focus of the first case study is optimization/synthesis of products in civil engineering. The focus of the second case study is optimization/synthesis of products in chemical engineering. However, in contrast to the first case study, which focuses on products alone, the complete (raw materials/production technologies/products) supply chain is considered and optimized. Both case studies are chosen to demonstrate the concepts of the proposed approach and the consequences of the different optimization criteria on the obtained solutions, and at the same time not to be numerically too challenging.

\subsection{Cantilever beam}

The first numerical example is simple example from the field of civil engineering. The example presents the synthesis/optimization of 150 equal cantilever beams. Each cantilever beam is 5.5 meters long beam, subjected to the combined effect of the dead-weight, the permanent continuous load of $9.0 \mathrm{kN} / \mathrm{m}(\mathrm{g})$ and the imposed variable continuous load of $12.0 \mathrm{kN} / \mathrm{m}$ (q) (Fig. 1).

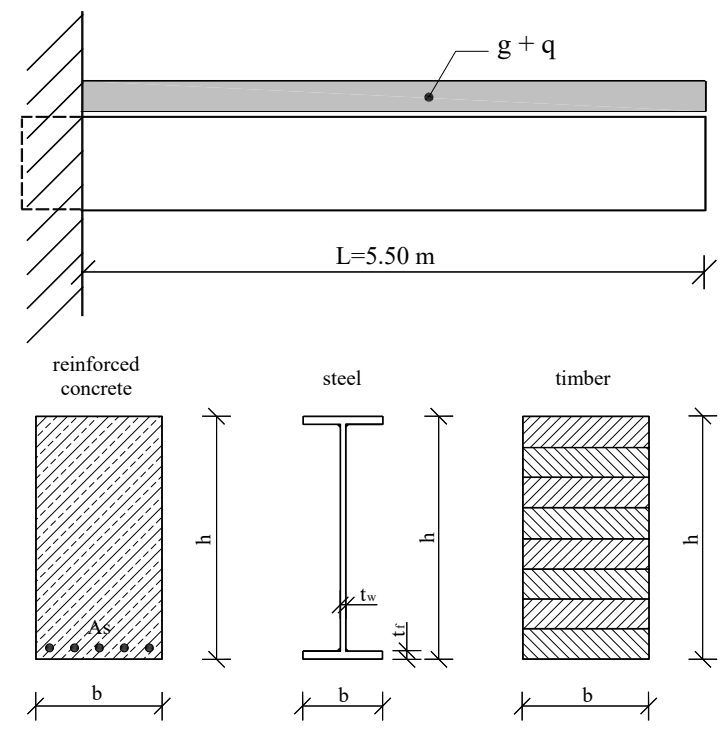

Figure 1: Cantilever beam. 
Each beam is proposed to be made from three different material alternatives: from the reinforced concrete, from the structural steel and from the laminated timber. In order to make the comparison and the competitiveness between these three materials, the rigorous synthesis of the beams was performed for various material and dimension alternatives, and for three different objectives/criteria, i.e. for the optimization of:

1. The economic profit;

2. The GHG emission caused by the production of the structure; and

3. The sustainability profit.

Since the defined synthesis problem of the beam is a discrete/continuous type optimization problem, the mixed-integer non-linear programming (MINLP) optimization approach was applied. Nine MINLP optimization models for the cantilever beam (CANTBOPT) were modelled as a combination between three different materials (concrete, steel and timber) and three different objective functions/criteria. As an interface for mathematical modelling and data inputs/outputs GAMS (General Algebraic Modelling System), a high-level language by Brooke et al. [7], was used. The models comprised the objective functions, subjected to the design, loading, resistance, dimensioning and deflection constraints known from structural analysis. The constraints were defined according to Eurocode specifications: Eurocode 2 [8] for the reinforced concrete, Eurocode 3 [9] for steel and Eurocode 5 [10] for timber. The beams were checked for the shear, bending moment and lateral torsional buckling resistances as well as for the allowances of deflections.

Three different superstructures were generated for three different materials. The reinforced concrete beam superstructure comprises seven different concrete grades, 13 standard reinforcing steel bars, 20 rounded dimension alternatives for the cross-section height and ten rounded dimension alternatives for the cross-section width (rounding up on whole 2.5 centimeters). The steel beam superstructure contains 3 different steel grades and eight different dimension alternatives of the standard steel plate thicknesses for flanges and webs separately. In addition, 35 different rounded dimension alternatives for the cross-section height and 11 rounded dimension alternatives for the cross-section width are involved in the timber beam superstructure.

The combination between the given material and dimension alternatives (binary variables) gives 18,200 different structure alternatives for the reinforced concrete beam, 192 different structure alternatives for the steel beam, and 385 structure alternatives for the timber beam. In this way, altogether $18,200+192+385=18,777$ different structure alternatives for the cantilever beam were defined for the synthesis.

Three different objective functions were defined for three different defined criteria. The first criterion of the synthesis includes the maximization of the economic profit $\left(P_{\mathrm{E}}[€]\right)$ of 150 equal beam structures. The profit is calculated as a sum/subtraction of the selling price, the self-manufacturing material and labor costs, and overheads. Three different objectives were defined for three different materials separately, see eqn (4). $N$ is a number of cantilever beams $(N=150), C_{\mathrm{S}}[€]$ is a selling price of a single cantilever beam, $C_{\mathrm{Mi}}[€ / \mathrm{kg}]$ represents the material unit prices of $(i \in I$ : concrete, reinforcing steel bars and formwork slab-panels for the concrete beam; structural steel, electrodes, gas consumption and anticorrosion-resistant paint for the steel beam; and timber, impregnation and protection paint for the timber beam). $\rho_{i}\left[\mathrm{~kg} / \mathrm{m}^{3}\right]$ and $V_{i}\left[\mathrm{~m}^{3}\right]$ are the corresponding unit masses and volumes, respectively. While $C_{\mathrm{L} j}$ stands for the hourly labor costs $[€ / \mathrm{h}], t_{j}[\mathrm{~h}]$ are times required for $(j \in J$ : placing, curing and vibrating of concrete, cutting and placing the reinforcement, and paneling the concrete beam; cutting, welding, painting the steel beam, and impregnating and painting the timber 
beam), and $f_{\mathrm{O}}$ is an indirect cost factor for overheads $\left(f_{\mathrm{O}}=2\right)$. For more information about cost items used in the economic objective function [11] and [12]

$$
\max P_{\mathrm{E}}=N\left(C_{\mathrm{S}}-C_{\mathrm{M} i} \rho_{i} V_{i}-C_{\mathrm{L} j} t_{j} f_{\mathrm{O}}\right) \quad[€] \quad i \in I, j \in J .
$$

The second criterion of the synthesis comprises the minimization of GHG emissions (in $\mathrm{CO}_{2}$ equivalent) caused by the beam production. Three different objective functions for the GHG emissions, $m_{\mathrm{GHG}}\left[\mathrm{kg} \mathrm{CO}_{2}\right.$ eq.], were defined for three materials separately, see eqn (5). The carbon footprint emission factor used in the study are $0.11-0.16 \mathrm{~kg} \mathrm{CO}$ eq. $/ \mathrm{kg}$ for concrete, $2.43 \mathrm{~kg} \mathrm{CO}$ eq. $/ \mathrm{kg}$ for the reinforcing steel bars, $1.72 \mathrm{~kg} \mathrm{CO}$ eq. $/ \mathrm{kg}$ for steel and $0.69 \mathrm{~kg} \mathrm{CO} 2$ eq. $/ \mathrm{kg}$ for timber

$$
\min m_{\mathrm{GHG}}=N f_{\mathrm{CFEFk}} \rho_{k} V_{k} \quad\left[\mathrm{~kg} \mathrm{CO}_{2} \text { eq }\right] \quad k \in K .
$$

The last criterion is the maximization of the sustainability profit, calculated for 150 beams as a summation/subtraction of the economic profit, eco costs of the global warming [5] and social profit. Three different objective functions were defined for three materials separately, see eqn (6). $C_{\mathrm{GW}}\left(€ / \mathrm{kg} \mathrm{CO}\right.$ eq.) is a price of global warming $\left(0.116 € / \mathrm{kg} \mathrm{CO}_{2}\right.$ eq. [4]) and $f_{\mathrm{SOC}}(€ /(\mathrm{h} \cdot$ worker $))$ is social profit coefficient $(5.056 € /(\mathrm{h} \cdot$ worker $))[2]$

$$
\max P_{\mathrm{SUS}}=P_{\mathrm{E}}+N\left(-C_{\mathrm{GW}} m_{\mathrm{GHG}}+f_{\mathrm{SOC}} f_{\mathrm{O}} t_{j}\right) \quad[€] \quad j \in J .
$$

\subsubsection{Cantilever beam optimizations results}

Table 1 shows results of optimization for three different materials and three different objective functions.

The obtained results show that the concrete beams exhibit the highest economic profit. The timber beams show the lowest GHG emissions and the highest sustainability profit. The steel beams exhibit the worst results in all three criteria.

\subsection{Biogas supply network}

The second example is an example of supply chains synthesis. The supply chain concept has become one of the main approaches to achieve efficiency of a given production process. The

Table 1: Results of the cantilever beam optimizations.

\begin{tabular}{|c|l|c|c|c|}
\hline \multirow{3}{*}{ Criterion } & & $\begin{array}{c}\text { Reinforced } \\
\text { concrete } \\
\text { C50/60 }\end{array}$ & Steel S 235 & Timber GL24h \\
\hline \multirow{3}{*}{1.} & Economic profit (€) & $\mathbf{2 7 , 9 0 3}$ & $\mathbf{- 7 0 , 5 1 5}$ & $\mathbf{2 6 , 2 9 2}$ \\
\cline { 2 - 5 } & b (cm) & 42.50 & 22.00 & 28.00 \\
\cline { 2 - 5 } & h (cm) & 57.50 & 73.00 & 84.00 \\
\hline \multirow{2}{*}{2.} & GHG emissions (kg) & $\mathbf{1 6 3 , 1 2 5}$ & $\mathbf{2 1 3 , 3 0 3}$ & $\mathbf{6 1 , 6 1 4}$ \\
\cline { 2 - 5 } & b (cm) & 42.50 & 22.00 & 20.00 \\
\cline { 2 - 5 } & h (cm) & 57.50 & 73.00 & 118.00 \\
\hline \multirow{3}{*}{3.} & Sustainability profit (€) & $\mathbf{3 4 , 6 2 7}$ & $\mathbf{- 7 5 , 9 6 7}$ & $\mathbf{4 2 , 7 1 5}$ \\
\cline { 2 - 5 } & b (cm) & 42.50 & 22.00 & 28.00 \\
\cline { 2 - 5 } & h (cm) & 57.50 & 73.00 & 84.00 \\
\hline
\end{tabular}

1. Economic profit; 2. GHG emission; 3. Sustainability profit. 
reason for this is that a production process or more generally an enterprise cannot be competitive without considering the supply network activities and interactions simultaneously. The supply chain considered in this example biogas supply network. The example is from the field of chemical engineering; however, its concept can be easily applied to other fields of engineering. The integrated supply network can be generally presented as shown in Fig. 2. In this specific example, the supply network follows the four-layer superstructure [13]:

- L1: Potential harvesting sites. This layer contains data relevant to the types of feedstocks. These are agricultural crops (corn, triticale and wheat grains), lignocellulosic crops (corn, grass, triticale and wheat silage, corn stover, and wheat straw), and manure (cattle, pig and poultry manure, poultry slurry and bedding). The data relates to their geographical availability and harvesting period; land area of each harvesting site, share of land area for growing agricultural crops and share of that area for growing crops for biomass production; feedstock unit cost; feedstock moisture content, dry matter content, density, and methane content.

- $\quad$ 2: Potential collection, storage and primary conversion facilities. The layer contains data relevant to production of intermediate products and by-products. The data relates to their conversion factors from feedstocks, fixed and variable cost for facility construction, unit cost of additional materials (glycerol, water, utilities), feedstock attrition during the storage, reference data for primary conversion facilities (energy consumption, production rate, minimum and maximum capacities, lifetime, fixed and variable labour cost, fixed and variable storage cost) etc. Technology included at L2 is anaerobic digestion.

- L3: Potential storage and secondary conversion facilities. This layer considers production of final product and by-products. The data relates to similar features as in previous layer with the difference that it refers to final products and by-products. Produced products and by-products, energy and waste can be (partly) recycled and used within layer L3 itself or within L2. Technologies included in L3 are cogeneration and dewatering technologies.

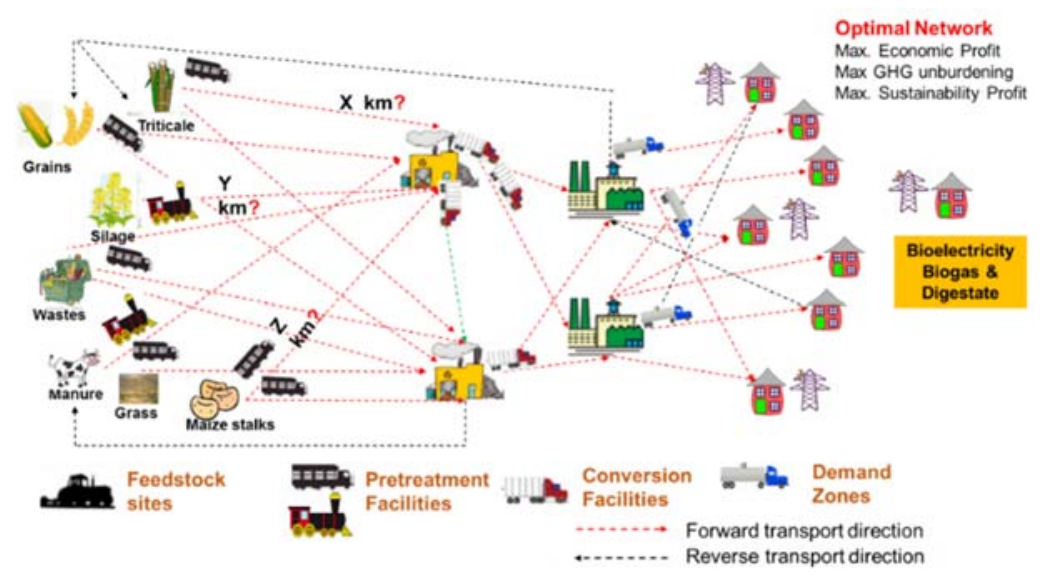

Figure 2: Integrated bio-power supply network superstructure. (Source: Modified from [14] and [15].) 
- L4: Demand. The final layer considers variability and demand of final products (bioelectricity) and by-products such as heat and digestate, and emissions (polluted water, $\mathrm{CO}_{2}$ emissions). The data relates to demand locations, quality and quantity of demanded products and by-products, their unit prices etc.

The case study was originally presented in [14] and represents an example of a biogas production plant in Slovenia. The locations harvesting sites, conversion sites and demand zones are presented in Fig. 3. The supply chain considered in the study accounts for:

- $\quad$ seasonality and availability of resources;

- $\quad$ storage of raw materials products and by-products at the locations of primary and secondary processing (L2 and L3);

- $\quad$ utilization of different transportation modes (road, pipeline, transmission);

- $\quad$ recycling of energy (plant and site-wide integration), products and waste.

The objective is to synthesize an optimal biogas supply chain under different objective functions: (i) maximization of profit; (ii) minimization of GHG emissions considering also unburdening besides burdening of the environment; and (iii) maximization of sustainability profit; while satisfying the feedstock quality and availability, and (by)-product quality, availability and demand constraints. The bioelectricity production constraint was set to $0.999 \mathrm{MW}$ by the guaranteed purchase of electricity sold to the grid at $155 € / \mathrm{MWh}$ [16].

The model was formulated as a MILP optimization problem and solved in GAMS. It is comprised of 19,444 equations, 31,170 continuous variables and 774 discrete $(0,1)$ variables.

\subsubsection{Biogas supply network synthesis results}

The optimal results for the three optimization scenarios are presented in Table 2. From Table 2 it can be seen that the main raw materials selected are poultry manure and slurry and corn, wheat and triticale silage. Among the manures, poultry manure and slurry are selected as their usage represent higher environmental unburden in comparison with cattle and pig manure and poultry bedding. In terms of environmental burdens, wheat and triticale silage

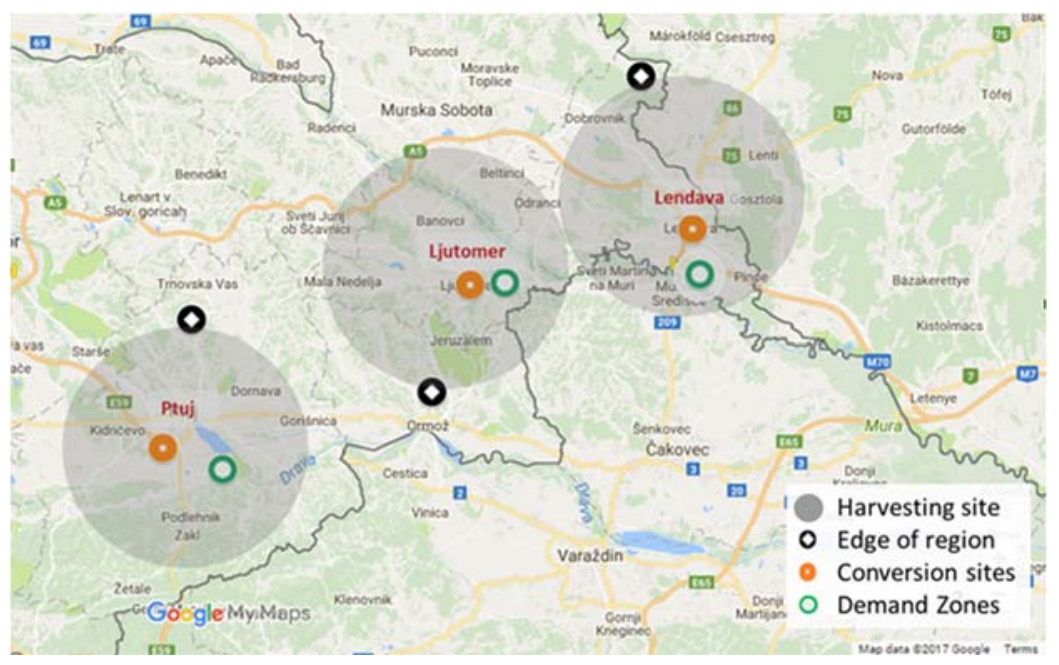

Figure 3: Possible locations of zones in the case study. (Source [13].) 
Table 2: Results for the biogas supply synthesis example.

\begin{tabular}{|c|c|c|c|}
\hline & $\begin{array}{c}\text { Maximal } \\
\text { economic } \\
\text { profit }\end{array}$ & $\begin{array}{c}\text { Minimal GHG } \\
\text { emission* }\end{array}$ & $\begin{array}{c}\text { Maximal } \\
\text { sustainability } \\
\text { profit }\end{array}$ \\
\hline \multicolumn{4}{|l|}{ Feedstock (kt/y) } \\
\hline Poultry manure & 16.28 & 18.73 & 13.98 \\
\hline Poultry slurry & 1 & 1 & 5.81 \\
\hline Corn silage & 6.52 & 1 & 8.81 \\
\hline Wheat silage & 1 & 0.33 & 1 \\
\hline Triticale silage & 1 & 7.55 & l \\
\hline \multicolumn{4}{|l|}{ Products } \\
\hline Electricity $(\mathrm{GWh} / \mathrm{y})$ & 8.19 & 8.91 & 8.91 \\
\hline Heat (GWh/y) & 9.70 & 10.55 & 10.55 \\
\hline Digestate $(23 \%$ dry solids, kt/y) & 21.21 & 25.06 & 21.57 \\
\hline \multicolumn{4}{|l|}{ Water (kt/y) } \\
\hline Purchased & 4.86 & 6.36 & 1 \\
\hline Recycled & 18.00 & 18.76 & 16.15 \\
\hline To be treated & 1 & & \\
\hline \multicolumn{4}{|l|}{ Utilities required $(\mathrm{GWh} / \mathrm{y})$} \\
\hline Electricity "recycled" & 1 & 0.71 & 0.71 \\
\hline Electricity purchased & 0.66 & 1 & 1 \\
\hline Heat "recycled" & 1.56 & 1.70 & 1.70 \\
\hline Heat purchased & 1 & 1 & 1 \\
\hline \multicolumn{4}{|c|}{ Dry matter, methane and manure content } \\
\hline Dry matter content $(\%)$ & 13 & 3.82 & 13 \\
\hline Methane content $(\%)$ & 59.79 & 60.82 & 59.39 \\
\hline Manure content (dry basis, $\%$ ) & 70 & 70 & 70 \\
\hline \multicolumn{4}{|l|}{ Economic results $(\$ / y)$} \\
\hline Economic profit (after tax) & 272,744 & $-1,388,220$ & 198,899 \\
\hline Eco-profit & 840,257 & 926,033 & 977,211 \\
\hline Social profit & 6,192 & 6,306 & 6,349 \\
\hline Sustainability profit & $1,119,222$ & $-455,881$ & $1,182,458$ \\
\hline $\mathrm{CO}_{2}$ eq. emissions (kt/y) & $-4,725 * *$ & $-5,526 * *$ & $-4,371 * *$ \\
\hline
\end{tabular}

*small weight is applied to simultaneously maximize sustainability profit.

** negative value means net unburdening of the environment.

perform better than other biomass sources. As they are more expensive than corn silage, the economic profit is significantly lower than when maximizing economic or sustainability profit. When considering sustainability, it is suggested to produce slightly more biogas and reuse renewable electricity and heat. In all the scenarios the manure content is set to its upper bound, to $70 \%$ (constraint is that between 30 and $70 \%$ of manure should be in the substrate mix based on the dry mass).

In terms of the social profit, the differences are relatively small as the production of electricity is fixed (0.999 MW). However, it can be seen that with greater capacity social profit is slightly increased. From results it could also be seen that in the case of maximal economic and sustainability profits, all the profits are positive with the most contributing factor of eco-profit. Both maximum economic and sustainable solutions are viable. 


\section{CONCLUSIONS}

It has become clear that the solutions to engineering systems must not only be feasible, but must also be beneficial to all the pillars of sustainable development (economic, environmental and social) to the greatest possible extent. Such holistic solutions have a great potential to provide the decision makers with invaluable support and contribute to good planning practices that could lead to a more sustainable economy.

The manuscripts presents a concept for obtaining such solutions. The approach is based on mixed-integer programming. The optimal solutions are obtained under different objective functions i.e. pure economic profit, GHG emissions, and sustainability profit. The concept was applied to two case studies: optimization of cantilever beam and biogas supply network. The results for first case study show that the concrete beams exhibit the highest economic profit while the timber beams show the lowest GHG emissions and the highest sustainability profit. The results for the second case study show that in the case of maximal economic and sustainability profits, all the profits are positive with the most contributing factor of ecoprofit. In both examples, the maximum economic and sustainable solutions are viable.

The obtained results give the insights into sustainable solutions from the overall sustainability viewpoint, and indicate that the selected metric provides good compromise solutions between economic, environmental and social pillars of sustainability. Although, on a short-term scale, the decision-makers might be primarily interested in economic profit, a portfolio of solutions that can be obtained using the proposed approach might provide invaluable support in making the decisions that promote long-term benefits for society and environment at a slightly lower economic performance.

\section{ACKNOWLEDGEMENT}

The authors are grateful for the support of funds from the Slovenian Research Agency (project L2-7633 and programs P2-0032, P2-0377, and P2-0129).

\section{REFERENCES}

[1] Kravanja, Z., Process systems engineering as an integral part of global systems engineering by virtue of its energy-environment nexus. Current Opinion in Chemical Engineering, 1, pp. 231-237, 2012.

[2] Zore, Ž., Čuček, L. \& Kravanja, Z., Synthesis of sustainable supply networks with a new composite criterion - sustainability profit. Computers and Chemical Engineering, 102, pp. 139-155, 2017.

[3] Zore, Ž., Čuček, L., Širovnik, D., Novak Pintarič, Z. \& Kravanja, Z., Maximizing the sustainability net present value of renewable energy supply networks. Chemical Engineering Research and Design, 2018. DOI: 10.1016/j.cherd.2018.01.035.

[4] The Model of the Eco-costs/Value Ratio (EVR), Delft University of Technology, www.ecocostsvalue.com/. Accessed on: 23 Mar. 2018.

[5] Vogtländer, J.G. et al., LCA-based Assessment of Sustainability: The Eco-costs/Value Ratio (EVR), VSSD: Delft, The Netherlands, 2010.

[6] Bogataj, M. \& Kravanja. Z., An alternative strategy for global optimization of heat exchanger networks. Applied Thermal Engineering, 43, pp. 75-90, 2012.

[7] Brooke, A., Kendrick, D. \& Meeraus, A., GAMS - A User's Guide, Scientific Press: Redwood City, CA, 1988.

[8] Eurocode 2, Design of concrete structures, European Committee for Standardization: Brussels 2004.

[9] Eurocode 3, Design of steel structures, European Committee for Standardization: Brussels 2005. 
[10] Eurocode 4, Design of timber structures, European Committee for Standardization: Brussels 2004.

[11] Kravanja, S., Žula, T. \& Klanšek, U., Multi-parametric MINLP optimization study of a composite I beam floor system. Engineering Structures, 130, pp. 316-335, 2017.

[12] Jelušič, P. \& Kravanja, S., Optimal design of timber-concrete composite floors based on the multi-parametric MINLP optimization. Composite Structures, 179, pp. 285293, 2017.

[13] Čuček, L., Lam, H.L., Klemeš, J.J., Varbanov, P.S. \& Kravanja, Z., Synthesis of regional networks for the supply of energy and bioproducts. Clean Technologies and Environmental Policy, 12(6), pp. 635-645, 2010.

[14] Egieya, J., Čuček, L., Zirngast, K., Isafiade, A., Pahor, B. \& Kravanja, Z., Synthesis of biogas supply networks using various biomass and manure types over multiple timeperiods. Computers \& Chemical Engineering, submitted for publication, 2018.

[15] You, F. \& Wang, B., Life cycle optimization of biomass-to-liquid supply chains with distributed-centralized processing networks. Industrial and Engineering Chemistry Research, 50(17), pp. 10102-10127, 2011.

[16] Decree on support for electricity generated from renewable energy sources; Government of the Republic of Slovenia for Legislation. Online. www.pisrs.si/Pis.web/pregledPredpisa?id=URED4718\#. Accessed on: 6 Jan. 2018. 